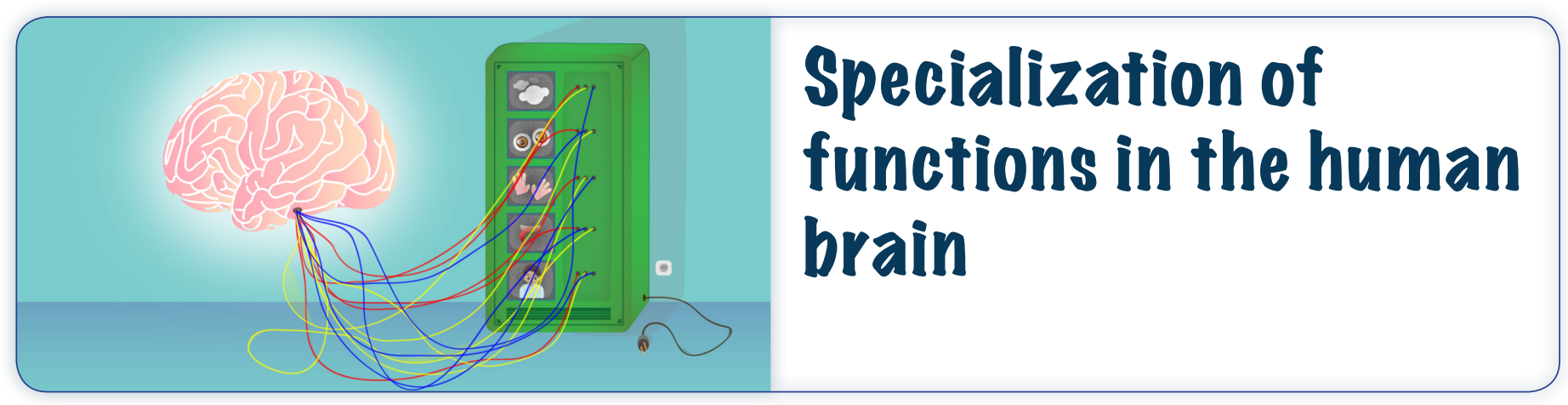

\title{
Josef Parvizi
}

\section{Department of Neurology, Stanford School of Medicine, Stanford, CA, USA}

\section{Reviewed by:}

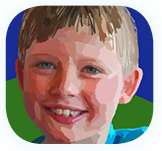

Madoc

11 years old
The brain has fascinated us for ages. Some of the first serious discussions about the human brain started in ancient Egypt where the king of Alexandria allowed live dissections of criminals for the study of human anatomy [1]. Those who performed the dissections opened up the skull bone and saw the brain live. When they cut through the brain, they discovered large spaces inside it. These spaces were connected to each other like chambers in a house. They were also filled with a unique looking, crystal clear fluid that we now know as the cerebrospinal, or brain, fluid. They were so excited about this finding! They thought the human soul resides in these fluid filled chambers. They tried to understand how the fluid moves across these chambers because they thought that this could explain how the human mind works.
Today, it sounds silly to say that the human mind is related to the flow of fluid across empty spaces inside the brain. But in those days, the practice of medicine was all about fluids inside the body and the balance between them. Doctors considered human health as a result of balance among different kinds of fluids inside the body. They were thinking in terms of fluids because the leading science at the time was about the practice of moving water from its source to a target, namely to a dry town or farm. There were no machines or computers to build a dam, but there were plenty of man-made channels and bridges to bring water from one location to another. Do a Google search on "aqueducts" and you will see amazing pictures of those water channels and bridges! In Egypt and nearby Middle East and Greece, they did not have a lot of rain. So they had to think very hard about fluids and how they could move fluids from one place to another. They were constantly thinking about fluids, and finding a set of chambers inside the brain that were connected to each other and filled with a unique looking fluid was a major breakthrough for them. They thought that they had found the place where the human soul resided!

As you can see, scientific theories of the day always follow the main practice of the day. When the main practice of the day was about fluids and their flow, scientists of the day tried to explain the brain function in terms of fluids and their flow inside the brain chambers. Today, the practice of the day is all about computers and computation, and so many scientists are trying to explain the human brain by saying that it works like a computer. In the next century, once society moves beyond computers, future generations 
will laugh at this and think that it was stupid to think that the brain works like a computer!

Before we move to our current age, let me tell you about Leonardo da Vinci. He was quite genius. He thought about the idea of the human soul residing in the brain chambers filled with its crystal clear fluid. He thought it just did not make sense to put the human soul in those chambers. What about other animals? Don't they have brains with fluid filled chambers? What if their chambers are bigger? Would you say that they have bigger souls? He went on to study the size and shape of brain chambers and showed that other animals like camels and goats also have brain chambers that are even more impressive in size than our own brain chambers [2]. A sane person would not say that camels and goats have larger minds than humans. So this whole idea must be crazy! In fact, in today's medicine, we agree with da Vinci. Larger brain chambers are a sign of severe psychiatric disorders such as schizophrenia!

Once the idea of fluid-filled brain chambers was ridiculed, one had to find other ways to explain how the human brain works. An Austrian scientist called Franz Joseph Gall promoted the idea that there are specific centers in the brain for specific functions [3]. This idea, known as phrenology, argued that if you use a part of your brain frequently, you become very good at it, and that particular brain area grows in size and creates a little bump in the skull bone. Let's say we have a math center in the brain. If you use math all the time, you become very good at it. You may become like Einstein. If that happens, your math center in the brain has grown a lot. If I study your skull bone, I should see a little bump over your head right over the math center. The same thing holds for brain centers for love, sex, emotions, language, etc. So if you study the bumps in the skull bone, you will be able to guess what that person is good at. You can call this crazy idea, "bumpology"! In fact, a lot of offices were specialized in studying bumps in heads and describing people's characters. If you wanted to marry someone, you could take your girlfriend or boyfriend to one of those offices and ask the "bumpologist" to predict if your bumps are compatible with the bumps of your partner-to-be.

We have come very far from those dark days of ignorance. We now know that the brain chambers cannot be the place where the human mind is stored. We also know that phrenology is not at all viable. The brain does not grow and it does not cause bumps in the skull [4]. Instead, we now know that the human mind is created in the brain by its 100 billion cells. More interestingly, unlike other cells in the body, brain cells have branches to connect with other cells and they talk to each other. The brain under the microscope is like a forest with a lot of branches that connect to nearby cells but also roots that travel far away to connect to remote cells. Because brain cells are connected together, brain functions are then created in a collective action of connected areas. It is like a city with different neighborhoods, and each neighborhood depends more or less on the other neighborhoods. But each neighborhood has its own character, and in the brain, we call "regionally specialized functions," meaning that each region of the brain is specialized to do a certain task.

Another fascinating thing about the brain is that its cells produce electricity, and that brain cells talk to each other by sending electrical signals. Now imagine that you are sitting in a helicopter and looking down at a dense forest. You see a lot of branches touching each other, but you do not hear much. If you now send a microphone down, you can start hearing all sorts of things: birds are singing, leaves are falling, monkeys jumping around, and jaguars are walking. So if you implant these spying microphones for days you will learn a lot of interesting stuff about the forest life. This is what I do for living: I listen to the sounds of the brain and try to understand how the brain works by recording the electrical activity from different corners of the brain. Listen to this video if you are interested in "sounds" of the brain.

We have recently begun to learn a lot about the brain function by simply eavesdropping on the electrical 
signals generated in different parts of the brain forest. We do this by implanting electrodes inside the brain (see Figure 1). These electrodes work like "spying microphones" implanted in different regions of the forest. We listen to the electrical activity and we try

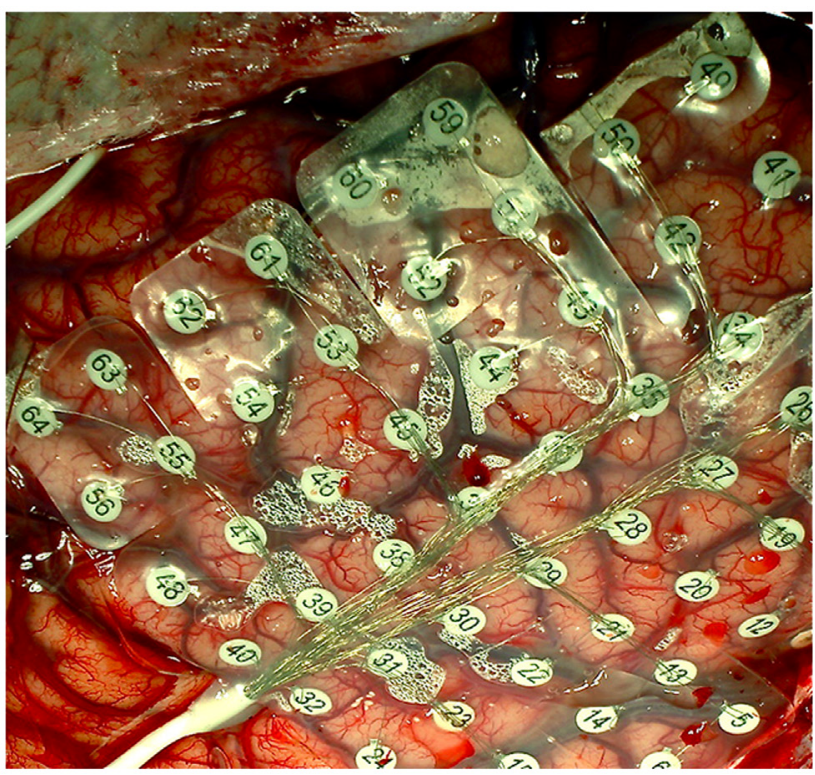

FIGURE 1 - In patients undergoing epilepsy surgery, a grid of electrodes is implemented over the bare surface of the brain. Each electrode serves as a spying microphone through which we can record electrical activity of a group of brain cells.

to decipher the code of such activity. To do this, we remove the skull bone and gain direct access to the surface of the brain.

But why do we do this? Well, there are patients who suffer from uncontrolled seizures. Their seizures are either wild convulsions of the whole body or mild staring spells into space and not being aware of what is going on around them. These abnormal states of brain function (i.e., seizures) are caused by abnormal electrical firing of some cells in some corners of the brain forest. We first treat the patients with medications, but if medications fail to help the patient, we then think about brain surgery. Yes, you guessed it right. We open the skull bone and implant a net of electrodes over the brain area that may contain the focus of seizures. We implant the electrodes like a net and wait for the seizure animal to come out of its hiding place. Once that happens, we know exactly which electrode recorded the seizure activity first, and we know which region of the brain is the origin of patient's seizures. By removing that area of the brain, we remove the "seizure cells" and make the patient seizure free.

During this waiting time, we ask the patients to participate in some experiments that are almost like computer games played from a laptop computer. For example, the computer screen flashes pictures of faces, guitars, body parts, landscapes, etc, or numbers and words like 2 , two, too, or 6 , six, sex, or 7 , seven, heaven. The patient is asked to just watch them carefully or read them aloud. We listen to the brain activity recorded from each different electrode and try to see if there are areas of the brain that care more about one versus another category.

Recordings in these patients have allowed us to examine the functions of neuronal populations in the human brain with amazing precision. In a recent study, we listened to electro-physiological activity in different regions of the brain in a patient implanted with electrodes inside the brain. As reported in our recent publication [5], we found increased buzz of electrical activity in response to viewing faces in a specific corner of the brain (Figure 2). What was so striking was the effect of perturbing the activity of this region while the patient was awake and looking around at faces or other objects in his room. We perturb the function of a brain area by sending $50 \mathrm{~Hz}$ electrical pulses through the pair of electrodes that are touching the brain. If you remember, the brain cells work with electricity. If you send additional electrical pulses at a random frequency of $50 \mathrm{~Hz}$, you make them confused. The procedure is called "electrical brain stimulation" or EBS. It is unfortunate to use the term "stimulation," because you do not literally "stimulate" the brain area. You just send electricity in there and confuse the cells. If you 


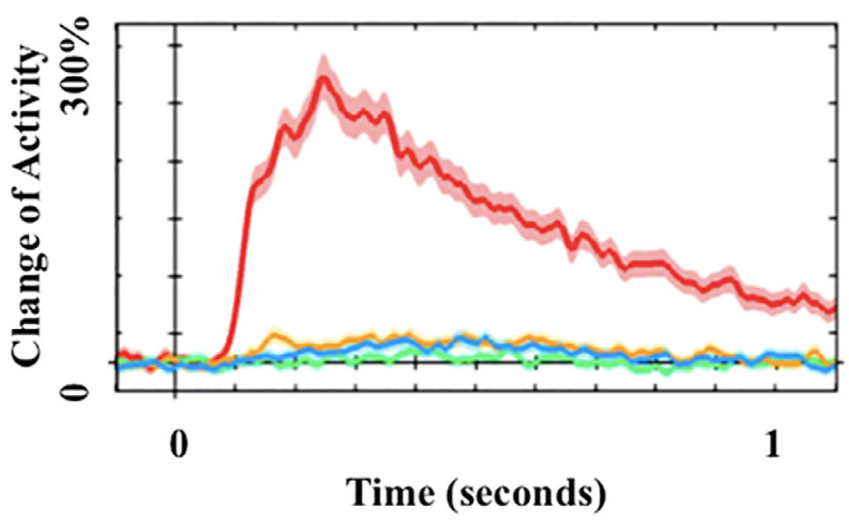

FIGURE 2 - Specialization of functions in the human brain.

Some cells in the brain are specialized for seeing faces. If you listen to the activity of these cells, you will see $\sim 300 \%$ activation (red) when the patient looks at faces. Almost no activation is seen when he looks at other pictures.

are interested to know what happens when you do EBS in different regions of the brain, see our paper that summarizes some of the most important EBS experiments in the last 100 years [6]. In the case of our patient with electrical stimulation of face areas, what we saw was astonishing. We had found groups of brain cells that were selectively activated when the patient saw pictures of faces. I asked the patient to look at my face and then I perturbed the function of these face-selective cells. He reported something amazing: He said my face got distorted! I turned into someone else! (You can see the video of this patient on the Journal of Neuroscience's website). This is clearly an example of the specialization of functions in the human brain.

In another study [7], we explored the response of a population of brain cells to a series of written symbols: numerals like “2," “6," “7”; number-words like "two," "six," "seven," or non-number words that sound similarly such as "too," "sex," "heaven," etc. Surprisingly, we found that in a specific location of the brain, cells start firing electrical signals when numerals are being seen, but almost no firing is seen when number-words or non-number words are seen. To explore this further, we showed the patients real numerals (red symbol 1 in Figure 3) or broken ones

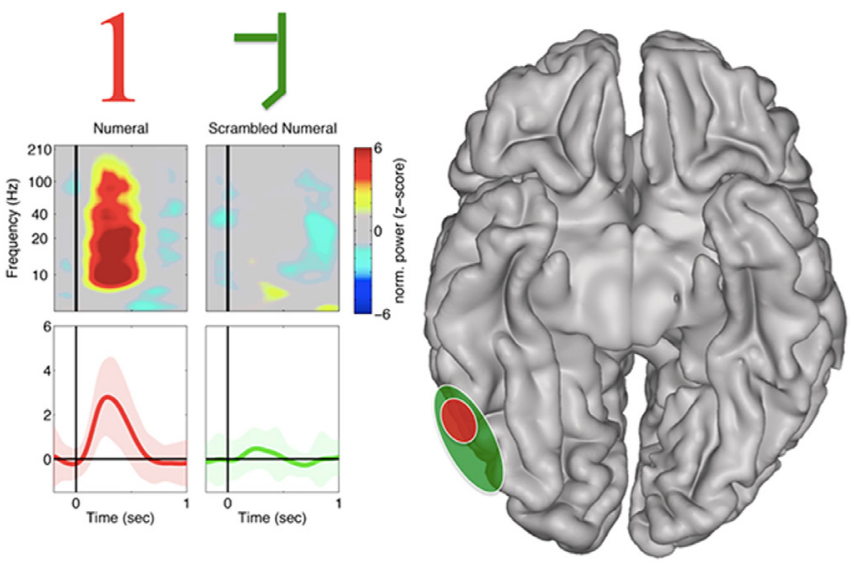

FIGURE 3 - Specialization of functions in the human brain through education. Some cells in the brain are specialized for seeing numerals. But numerals are cultural phenomena; we only learn to recognize them with education. If you listen to the activity of these "number" cells, you will hear a strong buzz of electrical activity (red) when the patient looks at numerals like "1" but no response to a broken and scrambled "1" (green). As explained in the text, a larger region of the brain nearby (green zone) responds to any kind of lines with branches. Monkeys must be using the same area of the brain when they jump from one tree branch to another.

(see green symbol in Figure 3). We discovered that the area of the brain responding to real numerals was located inside a larger area that responded to any kinds of wobbly lines, with angles and curves (like the broken numeral in green). What we think going on is that our tree-dwelling primate ancestors, and humans when they are born, perceive branches crossing branches, lines crossing lines, and they do that with the relatively larger area of the brain (green zone). However, with education, humans prune the activity of a select group of brain cells [8] (red zone) to respond to lines with specific angles and curves that denote "special" symbols we know as numerals. These symbols are special because they are very commonly seen in our culture and they have very specific meanings.

OK, let's conclude based on what we have reviewed so far. The brain is made of cells that make connections. A given brain function depends on the integrity of a network of cells that are connected together. Given that each brain site is connected 
with a specific set of brain regions, cells specialized for recognizing faces or numerals work like crucial nodes within a larger network of brain regions that work together. For example, when a face or numeral is seen, these specialized cells talk to other cells that have stored names of the faces or the meaning of the numerals or their sounds, etc. So all of a sudden, a set of brain regions get activated when a face or a numeral is seen, and we become automatically conscious of their meaning and significance. If the face is the face of someone we admire, we activate yet another region of the brain that is specialized for triggering the emotion of admiration, etc.

What we have not yet discovered is how the human consciousness is made possible. One thing is to have brain cells responding to faces and/or numerals, and the other thing is to have the conscious experience of knowing that it is me seeing that particular face and experiencing the admiration with your whole flesh and bone. How does firing electrical signals in the brain give rise to such vivid mental experiences? This remains to be discovered by your young minds interested in neuroscience. It will be so fascinating if you could discover how different regions of the brain work together and how their functions are synced and bound together. We have come very far from the fluid-filled chambers of the brains and bumps in the skull, but we are still far from understanding the brain function. The future is all yours, my friend! There is a lot to discover.

\section{REFERENCES}

1. Finger, S. 1994. The era of cortical localization. In Origins of Neuroscience, ed. S. Finger, 32-50. New York: Oxford University Press.

2. Damasio, A. R. 1994. Descartes' Error. New York: Putnam.

3. Gall, F. J., and Spurzheim, J. 1819. Anatomie Et Physiologie Du Systeme Nerveux En General Et Du Cerveau En Particular. Paris: F. Schoell.

4. Knight, R. T. 2007. Neuroscience: neural networks debunk phrenology. Science 316:1578-9. doi: 10.1126/science.1144677

5. Parvizi, J., Jacques, C., Foster, B. L., Witthoft, N., Rangarajan, V., Weiner, K. S., et al. 2012. Electrical stimulation of human fusiform face-selective regions distorts face preception. J. Neurosci. 32:14915-20. doi: 10.1523/JNEUROSCI.2609-12.2012

6. Selimbeyoglu, A., and Parvizi, J. 2010. Electrical stimulation of the human brain: perceptual and behavioral phenomena reported in the old and new literature. Front. Hum. Neurosci. 4:46. doi: 10.3389/fnhum.2010.00046

7. Shum, J., Hermes, D., Foster, B. L., Dastjerdi, M., Rangarajan, V., Winawer, J., et al. 2013. A brain area for visual numerals. J. Neurosci. 33:6709-15. doi: 10.1523/JNEUROSCI.4558-12.2013

8. Dehaene, S. 2011. The Number Sense: How The Mind Creates Mathematics. New York: Oxford University Press.

Submitted: 13 October 2013; Accepted: 30 October 2013; Published online: 13 November 2013.

Citation: Parvizi, J. (2013). Specialization of functions in the human brain. Front. Young Minds. 1:13. doi: 10.3389/frym.2013.00013

Copyright (C) 2013 Parvizi. This is an open-access article distributed under the terms of the Creative Commons Attribution License (CC BY). The use, distribution or reproduction in other forums is permitted, provided the original author(s) or licensor are credited and that the original publication in this journal is cited, in accordance with accepted academic practice. No use, distribution or reproduction is permitted which does not comply with these terms. 


\section{frontiers FOR YOUNG MINDS}

\section{REVIEWED BY:}

\section{Madoc, 11 years old}

Born in San Francisco, now lives in the ancient city of York, England, where the weather is more interesting. His favorite food is pizza and his favorite football team is Manchester United. He enjoys reading, Minecraft, soccer, hanging out with his friends, and critiquing the work of famous neuroscientists.
AUTHOR

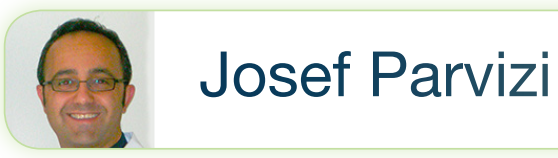

I am a medical doctor and a scientist. I work at Stanford University and treat patients with brain problems. I study the human brain by recording or electrically stimulating its activity with electrodes that we place over the surface of the brain in patients going through brain surgery. 